\title{
A literatura como arte do espetáculo ${ }^{1}$
}

\section{Resumo:}

Numa crónica de 1972, escrita a propósito do inquérito "Literatura em Portugal. O que é? Para que serve?", Maria Velho da Costa afirmou que "a boa escrita nunca é coisa do umbigo de cada um", evidenciando desde logo uma apetência para o diálogo e para a abertura no texto de corredores comunicantes entre todos os que preferem o ato de escrever, no pressuposto de que, como afirma no mesmo passo, "preferir o ato de escrever é descobri-lo gostoso e eficaz". Ver-se-á pelo conjunto da sua obra que o diálogo não se estabelece apenas ao nível da literatura, mas convoca diversas artes, línguas e registos discursivos. O prazer, mas também o desafio de ler Maria Velho da Costa, residirá precisamente na tenacidade e na ousadia com que a autora vai integrando e cruzando no seu texto diferentes modos de dar a ler, bem como uma multiplicidade de referências intra, inter e transtextuais que fecundam o discurso e o transformam num "mistério glososo", lúdico e performativo, que abre novas e muitas vezes inusitadas territorialidades semânticas. As parcerias que a autora tem vindo a estabelecer com profissionais do cinema, do teatro, das artes plásticas e da fotografia atestam essa apetência para o diálogo interartístico, para o malabarismo verbal e para o jogo cénico, traçando o perfil de uma escritora ávida e atenta ao movimento do mundo e à sensibilidade dos que, criativamente, o vão dizendo.

Palavras-chave:

performance, malabarismo verbal, jogo, crioulo galáctico

\section{Abstract:}

In a 1972 chronicle, in the context of the survey "Literature in Portugal. What is it? What is it for?", Maria Velho da Costa wrote that "good writing is never a matter of one's navel", showing right from the start a keenness for dialogue and for the creation of textual communication corridors among all those who prefer the act of writing, on the assumption that, as she affirms in the same excerpt, "to prefer the act of writing is to discover it tasty and effective". In fact, her literary work shows that dialogue happens not only at the level of literature, but calls for various arts and languages. The pleasure, but also the challenge in reading Maria Velho da Costa, comes precisely from the tenacity and boldness with which the author integrates and crosses in her text different ways of making it readable, as well as a multiplicity of intra, inter and transtextual references that nourish the text and turn it into a "glossy mystery", playful and performative, that opens to new and often unusual semantic territories. The partnerships established with professionals from the cinema, theatre, fine arts and photography confirm this appetite for inter-artistic dialogue, verbal jug- 
gling and performance, tracing the profile of an avid writer who is attentive to the movement of the world and to the sensitivity of those who keep saying it, by the use of their creativity.

Keywords:

performance, verbal juggling, play, galactic creole

Maria Velho da Costa afirmava, numa crónica de 1972, que "preferir o ato de escrever é descobri-lo gostoso e eficaz" (Ds: 40). Estes dois adjetivos denunciam uma parceria fundamental na obra da escritora: a aliança permanente entre o puro gozo linguístico e literário e a consciência da responsabilidade cívica em honrar e manter vivo e tenaz um legado de séculos. A associação entre esta vertente lúdica de fruição da língua e da escrita literárias e o exercício perseverante e "ardoroso" (o adjetivo é da autora) de manejar o material linguístico com eficácia têm vindo a fazer das obras de Maria Velho da Costa um "espetáculo". Esta expressão, que facilmente se associa ao chavão facilitista usado para economizar adjetivos e encurtar apreciações (qualquer coisa hoje é, indiscriminadamente, considerada um espetáculo) designa, como se sabe, o conjunto de atividades relacionadas com o teatro, a televisão, o cinema, a música, e tudo o que atrai o olhar ou a atenção e os prende. Ora, de tudo isto se constitui a obra da autora agora em apreço.

A paixão pela língua nasce cedo na autora e corporiza-se inicialmente nas redações muito elogiadas pelas freiras do colégio que frequentou em criança, na avidez de leitura e no fascínio posterior pela riqueza e versatilidade do material linguístico. Juntos, estes fatores viriam a determinar uma obra invulgar, marcada pela sedução pela palavra, pela escrita e pela arte de outros criadores e por uma pulsão irreprimível para o arrojo, o inconformismo, a provocação e a performance. De facto, esta é uma obra que, de variadas formas, se compraz em dar-se a ver, em exibir-se enquanto objeto artístico ou exercício lúdico, lembrando o que Schechner contempla na sua definição de "acting": "focused, clearly marked and framed behaviors specifically designed for showing" (Schechner 2013: 174).

Se, numa fase inicial, a tentação do uso subversivo da língua surgiu sobretudo como arma de arremesso contra os interditos familiares, sociais ou morais, depressa essa pulsão pelo uso libertador da palavra começou a ser direcionada no sentido da exploração da dissonância e da variância, em golpes de ousadia que abriram o caminho a múltiplas e inusitadas possibilidades de tessitura textual e novas territorialidades semânticas.

Laboriosa e comprometida no artesanato da palavra a que se propôs quando decidiu fazer da língua um "instrumento do real total" (C: 26), Maria Velho da Costa tem vindo a manejá-la em "compulsividade de registo" (CP: 83), para "entender o que nos comove e move para onde", objetivo que apresentou numa das crónicas de Cravo, em texto datado de dezembro de 1975 (C: 11). Esta vontade de saber de si (de nós) sabendo das coisas e chegando a elas pelo exer- 
cício linguístico surge logo no conto "Exílio Menor", inserido na coletânea O Lugar Comum, publicado em 1966. A personagem Lurdes, aluna do colégio de freiras "Tinha-se criado o direito de dizer coisas imprevistas e fora de propósito" (LC: 13) e exultava "com a perspetiva de mais uma vez tentar clarificar, abranger pelo poder miraculoso do verbo" (LC: 19-20), numa "fome de comunicar", em "cachoeira que a levava a rasgar sem jeito o obscuro da vida, em agitada melopeia, quieta, sentada no muro, a atentar no mecanismo do estar preso e a ver a liberdade sem mover-se" (LC: 21-22).

Esta fome de comunicar, acompanhada por um ouvido sempre atento ao mundo e aos outros, e por uma visão poliédrica, como é a da personagem Elisa, de Casas Pardas, determinou uma escrita feita do ouvisto, que acolhe as mais variadas contribuições e legitima a afirmação que a autora deixou numa crónica de Desescrita. Se, como aí afirma, a "boa escrita nunca é coisa do umbigo de cada um" (Ds: 40), ideia que também Bakhtine defende ao dizer que cada discurso "is full of transmissions and interpretations of other people's words" (Bakhtine 1981: 338), a obra de Maria Velho da Costa está aí para provar a sua apetência para o diálogo entre todos os que preferem o ato de escrever. O acervo literário que foi interiorizando e saboreando ao longo da vida é convocado em permanência na sua obra, num interessante trânsito que homenageia as suas afinidades eletivas e fecunda de sentidos o texto, abrindo-o a novas espacialidades semânticas. Ver-se-á, pelo conjunto da sua obra, que este diálogo não é apenas literário, mas interartístico, convocando diversas artes, línguas e registos discursivos, mas também modos do fazer artístico.

O gosto dialogante está desde logo manifesto na variedade da escrita desta autora, que se reparte pela ficção - em contos e romances -, pela crónica, pelo teatro e pela escrita argumentista e até lírica, de que são exemplo Da Rosa Fixa e Corpo Verde. Além disso, a parceria com artistas plásticos como Júlio Pomar, Teresa Dias Coelho, Óscar Zarate ou Ilda David, confirma a sua sensibilidade plástica, espelhada nas ilustrações de algumas obras suas, como Myra, $O$ Mapa Cor de Rosa, ou a primeira edição de $O$ Amante do Crato, na banda desenhada construída a partir do conto "Pérola e os Porcos", na colaboração que prestou na produção da obra fotográfica Das Áfricas, de José Afonso Furtado, ou ainda na abordagem que vários escritores portugueses empreenderam sobre a alegoria dos sentidos representada no conjunto de tapeçarias medievais "A dama e o unicórnio", em que a autora colaborou explorando o sentido da visão.

A partilha verifica-se igualmente ao nível da escrita literária propriamente dita. Se Novas Cartas Portuguesas é livro emblemático também ao nível do processo autoral, embora não se tenha tratado de uma escrita a três, mas antes de uma decisão de organização de textos partilhada, o roteiro cinematográfico Inferno, escrito em parceria com António Cabrita, e 0 Livro do Meio, romance epistolar concebido e construído em coautoria com Armando Silva Carvalho, atestam a versatilidade e a capacidade de diálogo artístico desta autora.

O gosto da partilha é também visível no atravessamento textual a que se assiste na sua obra. Na verdade, a autora considera-se, tal como a personagem Elisa, de Casas Pardas, um "cedro habitadíssimo" (CP: 345) por referências múltiplas e dá-lhes palco nas suas obras, convocando um fora-do-texto que se entretece com novos contextos. 
O prazer, mas também o desafio, de ler Maria Velho da Costa residirá precisamente na tenacidade e na ousadia com que a autora vai integrando e cruzando no seu texto diferentes modos de dar a ler, jogando com uma multiplicidade de referências intra, inter e transtextuais que fecundam o discurso e o transformam num "mistério glososo", ou num "ludus verboso" de efeito cénico, sempre irrequieto, às vezes íngreme, nunca anestesiante ou pacificador. Nele se dissolvem fronteiras e se atualizam em permanência os conceitos de pluralidade, polifonia, diálogo e influência sem angústia, exaltando a intertextualidade como estratégia de alargamento de sentidos, num dar-a-ler relacional.

É comum, nas suas obras, o leitor cruzar-se a cada passo com fiapos de poemas de Camões ou de outros autores consagrados, surpreender-se com réplicas de Shakespeare, ou até com frases emblemáticas de filmes ou de canções, que acordam no leitor reminiscências várias e o transportam para outra dimensão cultural, artística e autoral, que fecunda de sentidos o texto e o transforma num palco de cruzamentos interartísticos.

Atente-se nalgumas destas inclusões, retiradas do romance Myra: "Myra entende que o dia foi de passos em volta" - Herberto Hélder (M: 76); "Fiddledee, lérias, diz Myra, continuando aos tropeços. Sabia de cor tiradas de Vivien Leigh em Scarlett" - filme E tudo o vento levou - (M: 89); "Eu não fujo, eu vou contigo para algum lado. Home, disse como o ET, home" (M); - filme E.T.; "À distância ainda, numa clareira já brotada de trevo em campainhas amarelas e rosmaninho vivaz e tenaz, debaixo de uma azinheira que já não sabia a idade e frondosa, era um quadro de estranha paz e beleza" - Grândola Vila Morena, de Zeca Afonso (M); "O destino marca a hora" - Tony de Matos (M: 97). João de Deus passeia por vários textos, entre os quais Maina Mendes ("Debaixo daquela arcada / passava-se a noite bem") (MM: 101 e 152), Camões visita quase todos ("Todos conhecemos gente inteligente que reza, mas não rezam ao Pai. Rezam a ela e só a ela por prémio pretendida") (ICS: 14), da mesma forma que Shakespeare ("Hamlet sem fantasmas com a mãe afinal enfim feliz, feliz, feliz. E irmãos moiros, meio loiros. Como Vânia-Vanessa que punha e dispunha do pobre mito. O woman thy name is not frailty" (ICS: 49), mas também Bob Dylan e Joan Baez ("My love. My love loves me, O look the wonders I see, A rainbow locked in my window, My love loves me") ou Nana Mouskouri: "[...] berceuse d'amour, Chagrins d'amour durent toute la vie" (ICS: 139-140).

Por vezes, as línguas fulguram, à mistura com referências culturais e artísticas, numa espécie de happening rapsódico, onde as referências eclodem em instantâneos surpreendentes e se entrelaçam em fulgurante zapping, a lembrar o conceito de «pulsion rhapsodique» de Sarrazac (Sarrazac 1966: 17). Veja-se este excerto de Irene:

Raquel põe o CD da Callas mais alto. Nunca tinha ouvido que o mesmo são a música e as palavras. No amor, ninguém fala sozinho e até os mortos vão ao nosso lado.

Croce e delizia $O$ sink hernieder Nacht der Liebe my fair lady Meu amor não tenhas pressa longi di bo ke mí tem sufrido Croce e delizia al cor Si tu meurs et tu vas loin de moi Misterioso altero.

Raquel ouviu dizer que um dos sinais certos de possessão demoníaca é a poliglossia. Raquel acha que está delirante. (ICS: 169) 
Neste caso, o texto literário transporta o leitor até Lopes Graça, Maria Callas em La Traviatta, Tristão e Isolda, de Wagner, George Cukor e o filme My fair lady, o fado Vianinha, de Mariza, a canção Lua Nha, de Dani Silva e Edith Piaf, em Hymne à l'amour.

A transformação paródica é outra estratégia que provoca espetacularidade, pela criação de insólito: "A experiência é a cicatriz de todas as coisas" (CP: 22); "Eu bem sabia que não se devem pedir porcos às pérolas" (CP: 110); "o abominável homem das verves" (CP: 341); "A rata abriu as pernas e pariu-se o monte" (L: 44); "Pretidão de amor, tão brava a figura" (L: 251); "Para tão curto amor tão porca a cena." (ICS: 49); "Bolsei muita pena e muito dano" (M: 85); "O rapaz ri e os dentes são pérolas contadas" (M: 91).

Estes exercícios ilustram uma apetência pelo malabarismo linguístico, a "jonglerie verbal", de que se fala em Casas Pardas (CP: 242), onde a língua protagoniza combinatórias inusitadas, dialogantes e profundamente cénicas como acontece com a tradução brejeira do nome de Shakespeare, tornado "Pera tremente", "Abana a Pera", "Tio Guilherme - The Shakes" (CP: 13 e 109) ou a transformação das "Nursery Rhymes" em "Histery Rhymes", pelos efeitos devastadores da doença de Alzheimer (ICS: 45). Nestes exercícios, a palavra assume-se como expressão artística performativa no sentido em que se exibe em espetáculo de si, consciente da sua vocação para impactar o leitor.

As personagens comprazem-se neste malabarismo verbal e investem no jogo linguístico da variância paródica. Atente-se nestes dois excertos:

Subi aos meus quartos. A cadela seguiu-me. Raiava na piscina uma madrugada acrílica e escarlate. No espelho, a palidez de barro de um abexim, as olheiras roxas de um dervixe. Sou bem eu esta alma-penada? E um auto-colante de Nasi, jocoso e terno, que não o fez sorrir: Quando trazes a perigosinha para tua mãe botar defeito nela? Um beijo. Mummy. Porquê o giro crioulo-brasileiro da frase? Funcionavam já os tantans dos télélés das colunáveis? Mas Nasi não era sarcástica, nem metediça, pelo menos com ele. Quando era, era raro e merecido; ouvira-a uma vez dizer a um deputado enfatuado, que já ia, na mesma frase, na terceira vertente:

- Olhe, a mim, vertente faz-me sempre pensar em urinóis.

- É doença? - perguntou a esposa do arguente.

- Não, verter, 'tá a ver? - Vanessa explicitou, sacudindo o inexistente, e sumindo.

- São interessantes os seus piquenos. D'vera. (ICS: 178-179)

- Mas toda a gente escreve, Irene: no pano da loiça, no rego do tractor, no cabo da vassoura, na tecla da caixa e na Imitação dos Pássaros.

- Na limpeza da pele, no traço de Kohl e na pinta da testa; toda a gente escreve que se farta e não é só nas paredes e nas lenga-lengas - entrei eu.

- Tudo é literatura? Vocês acham?

- Não, Iria, isso é o que acompanha as embalagens dos medicamentos; literatura inclusa.

Rimos. Éramos assim. (ICS: 200) 
Os socioletos e a movimentação de diferentes línguas ajudam à variância e ao solavanco linguístico, celebrando o crioulo galáctico tão caro à autora:

Álcool, zilch. Passados, um nada. Identificação? Nem nada. Mas bastava olhar para eles. Um mulato, mas pouco, bem-falante:

- Senhor comandante, disse ao cabo - já que as coisas são o que são e a minha imberbidade lhe permite tratar-me por tu, aliás, como sabe, os negros são relativamente glabros, posso pedir-lhe o favor de retirar o s da segunda pessoa do singular? Não é tu que andastes a fazer? É tu que andaste. É assim que se dá cabo da língua, do Império, da autoridade.

[...]

- Chega, Orlando, Herr Rolf foi bem explícito: Letztes Mal. And no personal offense. Aux autorités.

- Ora muito bem, disse o cabo. Com ar entendido.

Orlando, de saída, deu-lhe o golpe de misericórdia, ensinou-lhe o ódio que não se desaprende:

Já pensastes, ó bófia, que teres razão, se não teres grão, não te dão o galão? Fôrassemos nós merda e tu cagar-nos mais. Porrada e tudo. (ICS: 72)

Vou fazer chichi, disse Vânia-Vanessa, não mexas em nada.

God forbid, disse Orlando.

Mas vai pensando, disse ela.

$[\ldots]$

Vas-y vite, disse Orlando.

Ma bo ca ta mixe.

Deus livre. (ICS: 46)

Nas obras de Maria Velho da Costa, o texto ganha dimensão performativa, no sentido em que se reivindica duma natureza de objeto artístico e lúdico, consciente de que a página é um palco e que nela tudo se passa "Comme au théâtre". Caberia aqui uma aproximação ao que Josette Féral designa por "framed theatrical space" (Féral 2002: 98), quando considera que o espetacular e a teatralidade têm de ter subjacente uma intenção teatral, uma consciência de alteridade que permite a passagem para um outro lugar, um espaço transicional, que se sabe ser de natureza ilusória ou ficcionalizada. Ora, em Maria Velho da Costa, há nitidamente uma intenção de espacializar o texto enquanto plataforma artística autoconsciente que se ostenta em espetáculo, em lugar de celebração da figuração e do lúdico. Este espírito percorre a escrita da autora e é assumido de forma explícita e insistente em Irene ou o Contrato Social, através da recorrência da expressão "Comme au théâtre" (ICS: 36, 57, 130, 135, 169, 170), embora se revele também em Casas Pardas, através da "Terça Casa" que configura uma peça de teatro a meio do romance, em Lúcialima e em Missa in Albis, bem como na criação da peça de teatro Madame. O gosto autoral pelo palco, pela mise-en-scène, pela pose estudada e de efeito cénico contagia personagens e ambientes, de tal forma que em Missa in Albis, por exemplo, as personagens adotam posturas dramáticas, poses cénicas, e discursos que são partes de réplicas teatrais ou 
para elas remetem, como é o caso da expressão “... já viu essa cena falhar num grande final?" (MA: 456).

O próprio tecido discursivo reivindica-se frequentemente como uma escrita dramática e toma até, por vezes, como acontece em Maina Mendes, um aparato de guião cinematográfico, com indicação de planos, de colocação das personagens e de incidência de luz: Veja-se um pouco desse aparato cénico:

O sol deve deslocar-se, em relação ao espaço do corredor sobre o qual directamente incide, por forma a que esse espaço se reduza, sem perder porém, devido aos limites impostos à incidência da luz pela forma rectangular das portas abertas, seus remates em ângulo recto. A alteração, que finalmente provoca o total retrocesso da zona fortemente iluminada para o quarto apenas, que é o de Maina Mendes, deve ocorrer por forma a tal ponto gradual que não possa ser imediatamente perceptível.

[...]

Quanto a Hortelinda, necessário é que, num movimento também gradual, mas este perceptível, e sempre apoiada à ombreira da porta que confina ao quarto donde veio e onde a luz, a amarela, é já no beiral da janela apenas, é necessário que, depois de coberta a cara com o avental, lentamente se vá sentando sobre os próprios calcanhares e chore. (MM: 85-86)

A par destas incursões pelos universos do trabalho dramatúrgico, em que o próprio texto esclarece os parâmetros do jogo figurativo que exibe, são vários os convites que se vão lançando ao leitor no sentido de que se veja no texto uma encenação e, nas personagens, atores em pose dramática. Em Irene, e sob focalização da personagem Orlando, a mãe, Nasi, é apresentada assim: "Parecia parva a dizer parvoíces e a vestir-se e a despir-se tudo no mesmo acto. Para a peça" (ICS: 33). E é o próprio Orlando que, na presença da mãe, adota a postura de quem segue um guião:

- Arranja-me um gin-tónico, Orlando, se faz favor.

Cool, man. Cool. E isto sem levantar a voz, nem a vista. Merecia um avanço cautelar.

Com ou sem gelo?

Vaidade de mãe vence sempre. Quando não derruba. Mas aquela não era o género. Se analiso agora estou feito.

Estendeu-lhe o copo, sem limão que ainda não havia no lote e também a hora não era a dessa adstringência. Fundo, respira fundo e compassado que é a regra de atinar donde vem o golpe. Sentar. Agitar o gelo com o dedo. Traçar perna. Esperar. A mãe olha enfim. Não perscruta, olha calma de cobra sem pálpebras para pestanejar. Olha o copo. $O$ dela. $O$ dele.

[...]

Arrebatado o primeiro lance. Como se lhe saísse o nove de espadas.

Orlando levantou-se, os olhos dela nas costas. Deu-lhe tempo a que ela os desviasse. Encostou-se em pose à lareira enchameada de hortenses azulonas.

$[\ldots]$ 
Parou. A mãe escutara-o, as mãos pousadas em concha aberta uma sobre a outra, as estrias escuras da fortuna sobre a pele aí rósea, os ombros lassos, e o enlevo frio da escuta. Comme au théâtre. (ICS: 34-37)

A própria personagem sabe-se um performer, tem consciência da sua ficcionalidade e exibe-a, encarando a sua vida e o seu discurso como objetos artísticos que ostenta em permanente representação, em "showing doing" (Schechner 2002:28):

Estudei mais que um assoprador de vidro da Marinha Grande, esperei mais e melhor que Marx, especializei-me mais que o David Bowie, I can play, I can play, diverti-me mais que o ... que o ... aqui é mais difícil - o Bill Gates, o ... o ... Bordalo Pinheiro. (ICS: 48)

A fuga desta personagem e as sucessivas identidades que teve de adotar são uma interessante figuração do jogo de máscaras em que se sustenta o romance: "Chegara mesmo a ousar César em Itália, embora não se consentisse muitas graças ao que punha em cena, em cada cena, a mesma cena" (ICS: 112). Quando regressa a casa, é a sua irmã que continua a encenação:

- Não sou Vânia nenhuma, é nome de tio taralhoco. Cut the cute. Põe-me no chão.

Disse isto com maldade e de um jacto. Tinha a réplica ensaiada, virou-lhe a cara ao beijo, as costas, e desapareceu. (ICS: 139)

Na mesma obra, Raquel, que é atriz, funciona como uma estratégia engenhosa para colorir o texto de dramaticidade, assumindo estar "Todo o dia em cena" (ICS: 66). E, de facto, tudo na sua vida parece confluir para um palco:

- To serve Thee and obey Thee.

Servir e obedecer. Mas que peça era esta? Raquel pensou que talvez não estivesse bem acordada. [...] O efebo (ela tinha de começar a defender-se de um dia tão raro) estendeu-lhe a mão para a ajudar a levantar-se. Comme au théâtre. (ICS: 135)

Esta dramaticidade da escrita de Maria Velho da Costa é ainda conseguida através da manutenção nos textos de um ambiente de ensaio e de jogo permanente, em que os mesmos textos vão e vêm, as réplicas mudam de locutor conforme a encenação em causa, num exercício verbal que se oferece em clara e assumida representação e, paralelamente, melhor justificam esta escrita como uma prática de irmandade, de comunicação partilhada e de livre-trânsito de textos e de vozes que não se deixam aprisionar nos limites de um determinado livro.

A literatura torna-se, assim, em Maria Velho da Costa, uma arte do espetáculo que abre interessantes e inusitadas "zonas de convivência" (Mateus 2002) entre diferentes práticas artísticas. Trata-se, porém, e sempre, de um exercício linguístico tenaz e adstringente, por- 
que impeditivo de comodismos ou entorpecimentos por parte de quem acede aos textos da autora. O seu percurso foi cimentado no fascínio pela língua e pelas potencialidades desse "verbo-história português" (C: 84) de que é preciso fazer eco, comprometendo-se, e convocando outros escritores, para a sua preservação enquanto fator de identidade cultural nacional, interpelando-os a que estimulem o seu conhecimento profundo e a destreza no seu manuseio para que, como diz em Cravo, não "se estanque no povo a vocação de indagar do difícil e do trabalhado" (C: 85). Nesse sentido, os textos de Cravo e de Desescrita, balizam a produção literária da autora e contextualizam as suas opções discursivas, que mantêm e honram a vitalidade da língua e o seu legado literário, mantendo viva a memória de textos e autores e chamando-os a dialogar com a contemporaneidade.

Nessas crónicas do período revolucionário, a escritora brandia a língua como voz ativa face ao poder e insurgia-se contra os criativos "a soldo" (Ds: 41) que, pelo seu dizer fácil, ratificavam o analfabetismo do povo e fomentavam o entorpecimento mental e o unanimismo, coartando o poder enérgico da língua na sua capacidade de desencadear a indagação. Hoje, o conjunto da sua obra está aí para atestar a coerência de um percurso onde a escrita é atividade subversiva, porque agitadora da pacatez amorfa e acrítica, e exercício sempre comprometido, enquanto permanente indagação sobre o mundo e a sua ordem ou as suas desordens. Mesmo em plena ditadura, a autora brandia o seu texto espetacularmente e reagia assim à imposição de uma escrita conveniente:

Ecidi escrever ortado; poupo assim o rabalho a quem me orta. Orque quem me orta é pago para me ortar. Também é um alariado. Também ofre o usto de ida. Orque a iteratura deve dar sinal da ircunstância, e não tem ustificação oral. E ais deve ter em conta todos os ofrimentos, esmo e rincipalmente os daqueles ujo rabalho é zelar pela oralidade e ordem ública - os ortadores.

[...] A iteratura eve ser uma oisa éria e esponsável. Esta é a minha enúncia ública. (Eço esculpa de esitar nalguns ortes, mas é por pouco calhada neste bom modo de scrita usta ao empo e aos odos).

[...] Olegas, em ome da obrevivência da íngua, vos eço pois:

Reinai-vos a ortar-vos uns aos outros

Omo eu me ortei. (Ds: 55-56)

Esta é uma escrita comprometida, desassombrada e sempre assombrosa, porque se insurge contra as vozes passivas, mas também contra as leituras passivas, contra os que usam a língua, ou a literatura, em atitude de subserviência ou de covarde e alienada mansidão. Hoje, como nos anos fervilhantes da revolução dos cravos, a escrita de Maria Velho da Costa mantém-se fiel ao compromisso de ser "barragem contra a voz passiva" (CP: 83), em desafio altaneiro e singular. Na literatura portuguesa, e convocando uma frase sua retirada do livro Da Rosa Fixa, "Nunca nada foi ainda comparável” (DRF:43). 
Cadernos de Literatura Comparada

A literatura como arte do espetáculo

\section{NOTAS}

* Maria José Carneiro Dias é professora na Escola Secundária de Paços de Ferreira, onde tem vindo a lecionar a disciplina de Português, e onde codinamiza o grupo de teatro Máscaras. Depois de um mestrado em Estudos Literários, Culturais e Interartes, em que abordou a ficção de Amin Maalouf enquanto estratégia de mediação simbólica entre Ocidente e Oriente, fez um doutoramento em Literatura Portuguesa com uma tese sobre Maria Velho da Costa e a sua poética de au(c)toria. É membro integrado do ILCML, onde tem desenvolvido trabalho no âmbito do grupo Inter/ Transculturalidades.

${ }^{1}$ As indicações bibliográficas referentes ao corpus de leitura em análise, bem como as relativas às obras não ficcionais publicadas pela autora estão identificadas pelas respetivas iniciais, conforme se indica:

Ficção: O Lugar Comum - LC; Maina Mendes - MM; Casas Pardas - CP; Lúcialima - L; Missa in Albis - MA; Dores - D; Irene ou o Contrato Social - ICS; O Livro do Meio - LM (em coautoria); Myra - M.

Não Ficção: Desescrita - Ds; Cravo - C; Da Rosa Fixa - DRF.

\section{Bibliografia}

Bakhtine, Mikhail Mikhailovich (1981), The Dialogic Imagination - Four Essays -, Austin, University of Texas Press.

Barthes, Roland (1984), Le bruissement de la langue - Essais critiques IV, Paris, Éditions du Seuil. Compagnon, Antoine (1979), La seconde main - ou le travail de la citation, Paris, Éditions du Seuil.

Costa, Maria Velho da (1973), Desescrita, Porto, Afrontamento.

- - (1979), Casas Pardas, Lisboa, Moraes Editores, $2^{\mathrm{a}}$ edição.

- (1983), Lúcialima, Lisboa, Edições «O Jornal».

- - (1988), Missa in Albis, Lisboa, Publicações Dom Quixote.

-- (1994), Cravo, Lisboa, Moraes Editores (2 $2^{\mathrm{a}}$ edição: 1994, Lisboa, Publicações D. Quixote).

- - (1999), Da Rosa Fixa, Lisboa, Quetzal Editores, $2^{\mathrm{a}}$ edição.

- (2001), Maina Mendes, Lisboa, Publicações D. Quixote, $4^{\mathrm{a}}$ edição.

- (2001), Irene ou o Contrato Social, Lisboa, Publicações Dom Quixote, $2^{\mathrm{a}}$ edição.

-- (2002), O Amante do Crato, com um desenho de João Cutileiro, Porto, Edições Asa. 
-- (2003), Dores, Lisboa, Publicações Dom Quixote, $1^{\text {a }}$ edição de bolso.

-- (2006), e Carvalho, Armando Silva, O Livro do Meio, Lisboa, Editorial Caminho.

- (2008), Myra, pinturas de Ilda David, Lisboa, Assírio e Alvim.

Dias, Maria José Carneiro (2018), Maria Velho da Costa - uma poética da au(c)toria, Lisboa, Imprensa Nacional.

Féral, Josette (2002), "The Specificity of Theatrical Language", Substance, vol. 31, № 2/3 Issue 98/99: Special Issue: Theatricality, The Johns Hopkins University Press: 94-108.

- - (2009), Por uma poética da performatividade: o teatro performativo, tradução de Lígia Borges, pp.197-210, documento pdf acessível em http://www.revistas.usp.br/salapreta/article/ view/57370/60352.

Mateus, José Alberto Osório de Almeida (2002), "Teatro e Literatura", in Brilhante, Maria João/ Camões, José e Silva, Helena Reis (orgs.), De Teatro e Outras Escritas, Lisboa, Quimera, Centro de Estudos de Teatro: 212-218.

Sarrazac, Jean-Pierre (1981), L'Avenir du Drame - Écritures Dramatiques Contemporaines, Lausanne, L'Aire Théatrale.

-- (1996), « Le Retour au Théâtre », in Communications, vol. 63, nº 63, acessível em linha em www.persee.fr/web/revues/home/prescript/article/comm_0588-8018_1996_nur.

- - (2005) [dir.], Lexique du drame moderne et contemporain, Belvel, Circé.

Schechner, Richard (2013), Performance Studies, an Introduction, New York, Routledge, 3rd Edition, [with integrated companion website, media editor, Sara Brady], doc. pdf.

Topia, André (1979), “Contrapontos Joycianos”, Intertextualidades («Poétique», nº 27), Coimbra, Livraria Almedina: 171-208. 